\title{
PRÁTICAS DA EDUCAÇÃO AMBIENTAL: UMA PROPOSTA DE EDUCAÇÃO PARA O DESENVOLVIMENTO SUSTENTÁVEL
}

\author{
David Luiz Marsaro Didonet ${ }^{1}$ \\ Jackeline Pires de Souza ${ }^{2}$ \\ Talita do Amaral e Souza ${ }^{3}$
}

\begin{abstract}
RESUMO
O objetivo geral do artigo é a apresentação do surgimento de uma visão do Desenvolvimento Sustentável associada ao movimento de Educação Ambiental enquanto proposta de levantar a trajetória e as práticas comuns existentes na aplicação de ambos os conceitos. São apresentadas de forma cronológica diferentes conferências internacionais e regionais, associadas ao desenvolvimento sustentável, que realizaram por intermédio da UNESCO. Entendimentos e conceito de desenvolvimento sustentável, na perspectiva de dirimir mitos e concepções ingênuas serão expostos. A educação, nas suas diversas possibilidades, abre espaço para um repensar de práticas sociais, com base numa adequada compreensão essencial do meio ambiente global e local. Deste modo, a Educação Ambiental (EA) mostrada como ferramenta importante para conscientizar, motivar e sensibilizar as pessoas e se faz necessária para que se haja o entendimento e o pensamento sobre o que é o Desenvolvimento Sustentável. São apresentados os principais eventos intergovernamentais que deram surgimento à concepção de EA e as principais diretrizes e recomendações para sua aplicação. Finalizando, o artigo demonstra a necessidade de se haver um processo educacional, que envolva principalmente os paradigmas da EA, para que se construa um desenvolvimento sustentável que prepara o homem para viver de forma responsável em seu meio ambiente. A EA deve estar incluída em todas as oportunidades de ensino, como um processo contínuo e estender para fora das instalações escolares, de modo a considerar o meio ambiente em suas múltiplas dimensões. Nesse sentido, o papel dos educadores professores (as) é essencial para impulsionar as transformações de uma educação que assume um compromisso com a formação de valores de sustentabilidade, numa perspectiva coletiva.
\end{abstract}

Palavras-Chave: Práticas. Educação Ambiental. Desenvolvimento Sustentável

\section{PRACTICES OF ENVIRONMENTAL EDUCATION: A PROPOSAL OF EDUCATION FOR SUSTAINABLE DEVELOPMENT}

\begin{abstract}
The general purpose of the article is the presentation of the emergence of a vision of sustainable development associated with the movement of Environmental Education (EE) and a proposal to raise the trajectory and the common practices existing in the application of both concepts. The various international and regional conferences related

\footnotetext{
${ }^{1}$ Professor Esp. Faculdade Pitágoras de Teixeira de Freitas. Email: dlmdidonet@hotmail.com;

${ }^{2}$ Professor Esp. Faculdade Pitágoras de Teixeira de Freitas. Email: jspjack@ hotmail.com;

${ }^{3}$ Professor Esp. Faculdade Pitágoras de Teixeira de Freitas. Email: talita-1987@ hotmail.com
} 


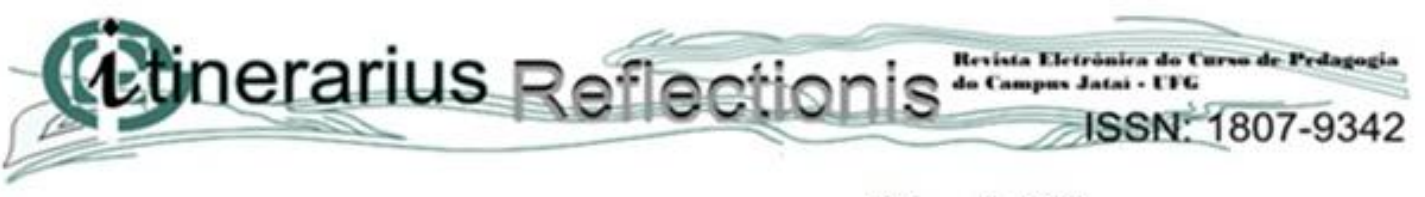

v.11, n. 1,2015

to sustainable development, which took place through the UNESCO are presented chronologically. Understanding and concept of sustainable development with a view to resolve myths and naive conceptions will be exposed. Education in its various possibilities, opens a stimulating space to rethink social practices, based on an appropriate essential understanding of the global environment and local. Thus, environmental education is shown as an important tool to educate, motivate and raise awareness and is necessary so that if there is understanding and thinking about what is Sustainable Development. The paper also presents the main intergovernmental events that gave rise to the concept of EA and the main guidelines and recommendations for your application. Finally, the article demonstrates the need to be an educational process, which mainly involves the paradigms of environmental education, in order to build a sustainable development that prepares man to live responsibly in their environment. EA must be included in all educational opportunities, as an ongoing process and extend out of school facilities in order to consider the environment in its multiple dimensions. In this sense, the role of teacher educators (as) it is essential to boost the transformations of an education that assumes a commitment to the formation of values of sustainability, a collective perspective .

Keywords: Practices, Environmental Education, Sustainable Development

\section{INTRODUÇÃ̃O}

Durante as últimas décadas, diversas Conferências Internacionais debateram a problemática ambiental e a necessidade da construção de um novo modelo de produção sustentável, apoiado em bases ecológicas, que criticasse o novo modelo de modernidade, sob a perspectiva de novos valores e saberes. Pode-se citar a Conferência de Estocolmo (1972), a Conferência de Tbilisi (1977) e a Eco-92 realizada no Rio de Janeiro que contaram com a participação de governos, Organizações Não Governamentais e sociedade civil no debate do tema. Todas elas corroboraram a importância da construção de um desenvolvimento sustentável e de um processo educacional que preparassem o homem para a convivência harmoniosa e responsável com o seu meio ambiente.

Tanto as palavras meio como o vocábulo ambiente passam por conotações diferentes, quer na linguagem científica, jurídica, administrativa ou outra. Nenhum desses termos é unívoco. Meio ambiente foi uma expressão consagrada na língua portuguesa, definida como "o conjunto de condições, leis, influências e interações de ordem física, química e biológica, que permite, abriga e rege a vida em todas as suas formas", isso segundo a Lei Federal n 6938 de 31 de Agosto de 1981 e, portanto, é o 


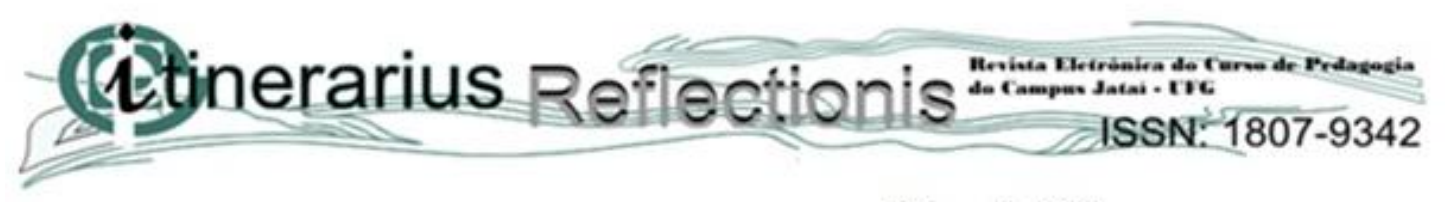

$$
\text { v.11, n. } 1,2015
$$

resultado da interação do conjunto de elementos naturais, artificiais e culturais que propiciem o desenvolvimento da vida em todas as suas formas.

Nos últimos séculos um modelo de civilização alicerçado no modelo industrial, se impôs, proporcionando o desenvolvimento de novas tecnologias que tornaram o homem capaz de exercer cada vez mais influência sobre o meio ambiente, acarretando ao Planeta uma acelerada degradação, que compromete a qualidade e sobrevivência humana na biosfera e seu desequilíbrio. À medida que tal modelo de desenvolvimento econômico passou a provocar efeitos negativos mais graves, surgiram manifestações e movimentos que enfrentam a crise ecológica e que refletiam a consciência de parcelas da população.

E diante deste contexto de inquietação que surgiu de maneira explosiva há duas ou três décadas, foi evidenciado um grande número de ferramentas surgidas por todo o mundo com o objetivo de consolidar conceitos como educação ambiental e desenvolvimento sustentável. Como será visto, há diversos entendimentos sobre essas duas concepções. Neste artigo, defende-se a ideia de que, embora sejam concepções diferentes, elas se completam. Nessa direção, este artigo busca mostrar que a educação ambiental representa a possibilidade de motivar e sensibilizar as pessoas, permitindo transformar as diversas formas de participação em potenciais fatores de dinamização da sociedade desta forma, garantir práticas e ações que garantam o desenvolvimento sustentável.

\section{AS CONFERENCIAS DA ONU E O DESENVOLVIMENTO SUSTENTÁVEL}

A popularização do conceito de desenvolvimento sustentável se observam a partir de alguns referenciais que agregam à dimensão do discurso propostas de sustentabilidade ambiental, social e de desenvolvimento, como é o caso das conferências internacionais, regionais e nacionais, sobre o meio ambiente, muitas delas tendo a Unesco como promotora ou apoiadora. Diversas Conferências patrocinadas pela Organização das Nações Unidas - ONU inserem-se no contexto dos esforços de 


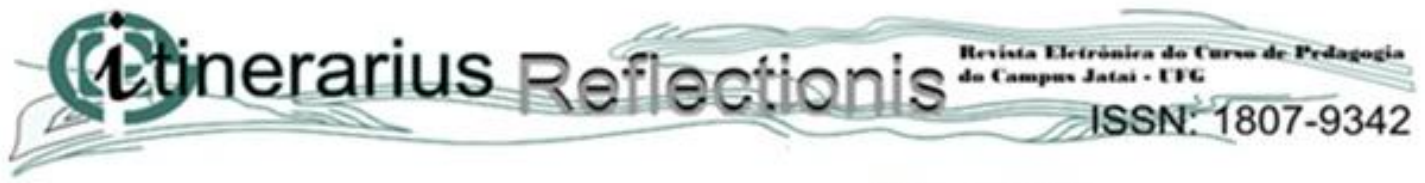

v.11, n. 1,2015

diferentes atores sociais, sobretudo nas três últimas décadas, para associar as agendas de desenvolvimento e meio ambiente.

Entre as décadas de 1960 e 1980, cientistas, movimentos ambientalistas e uma gama de políticos e funcionários públicos denunciaram os problemas ecológicos e sociais das economias herdeiras da Revolução Industrial. Em resposta à crescente preocupação pública com os efeitos negativos do modelo industrial, a Organização das Nações Unidas (ONU) iniciou um ciclo de conferências, consultas e estudos para alinhar as nações em torno de princípios e compromissos por um desenvolvimento mais inclusivo e harmônico com a natureza. (BARBIERI \& SILVA, 2011).

A degradação sistemática de recursos naturais e os impactos negativos desta degradação possibilitaram o surgimento de um conceito de desenvolvimento sustentável. Muitos pensam que o conceito foi criado durante a Rio 92. Na verdade a primeira corrente interpretativa (econômica e técnico-científica) nasce bem antes: sua origem é da década de 1970, quando se formou na Itália o Clube Roma, que reuniu um grupo de especialistas de vários países para debater o futuro do Planeta. Publicado sob o título de "Limites do Crescimento", em 1972, onde ficou provado, através de números, que o progresso científico e tecnológico estava criando um perigoso confronto entre o conforto humano imediato e a preservação da vida no nosso planeta. A segunda corrente, relacionada com a crítica ambientalista ao modo de vida contemporâneo, e que se difunde a partir da Conferência de Estocolmo em 1972, a primeira a associar de forma consciente as questões ambientais ao Desenvolvimento Sustentável, promovendo visibilidade pública à questão ambiental e colocando-a na pauta internacional (JACOBI, 2005).

$\mathrm{Na}$ busca de se garantir um equilíbrio justo entre as necessidades econômicas, sociais e ambientais das gerações presentes e futuras e firmar apoios entre os países desenvolvidos e em desenvolvimento, iniciou-se um processo que conduziu à Conferência das Nações Unidas sobre o Meio Ambiente e o Desenvolvimento - a Rio 92, governos reuniram-se na cidade do Rio de Janeiro, para Conferência da Terra, representando o primeiro passo de um longo processo de entendimento entre as nações.

Já em 2002, a Comissão sobre o Desenvolvimento Sustentável das Nações Unidas (CDS) organizou a Conferência Mundial sobre Desenvolvimento Sustentável 


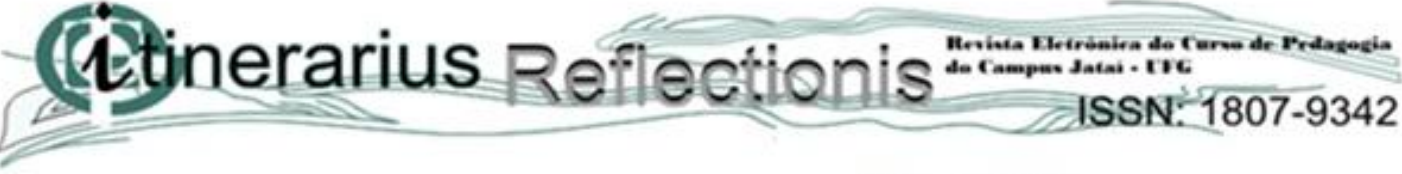

v.11, n. 1,2015

em Johannesburgo, África do Sul. Essa conferência reuniu chefes de Estado e de Governo, organizações não governamentais e empresários, que revisaram e avaliaram o progresso do da Agenda 21. A meta geral da Conferência foi, de forma coletiva, assumir a responsabilidade de fazer avançar e fortalecer os pilares interdependentes e mutuamente apoiados do desenvolvimento sustentável nos âmbitos locais, nacional, regional e global (GONÇALVES, 2005).

Pode-se afirmar que chegamos ao século XXI com um conceito de desenvolvimento sustentável mais amadurecido, que não se refere apenas a um problema que se limita a promover adaptações ecológicas de um processo social, mas a um modelo múltiplo para a sociedade, que se deve considerar a viabilidade econômica como a ecológica. Esse conceito não está apenas restrito as discussões acadêmicas e políticas, a expansão da consciência coletiva com relação ao meio ambiente se popularizou por todos os continentes, passando a fazer parte da vida cotidiana das pessoas. Promovendo assim uma mudança substancial do próprio processo civilizatório levando à necessária redefinição das relações sociedade humana/ natureza.

\section{EDUCAÇÃO AMBIENTAL - A COMPREENSÃO DOMINANTE}

A educação, nas suas diversas conjunturas, permite um estimulante espaço para um repensar de práticas sociais, com base numa adequada compreensão essencial do meio ambiente global e local, da interdependência dos problemas e soluções. Freire (2000) escreveu: Se a educação sozinha não pode transformar a sociedade, tampouco sem ela a sociedade muda. Neste contexto, a educação não pode restringir-se a problemas individuais, faz-se necessário construir uma sociedade planetária mais equitativa e ambientalmente sustentável, desta forma a educação deve atingir uma dimensão ético-política, a fim de contribuir para a solução de problemas hoje tão graves, que dizem respeito à própria sobrevivência da humanidade.

Em diversos contextos, mundiais e locais, a educação ambiental tem sido tratada como um importante instrumento de transformação social, resultando em documentos relevantes para a visibilidade dessa questão. Sem dúvidas, a educação ambiental vem conquistando espaço e tem representado um papel relevante nos últimos 


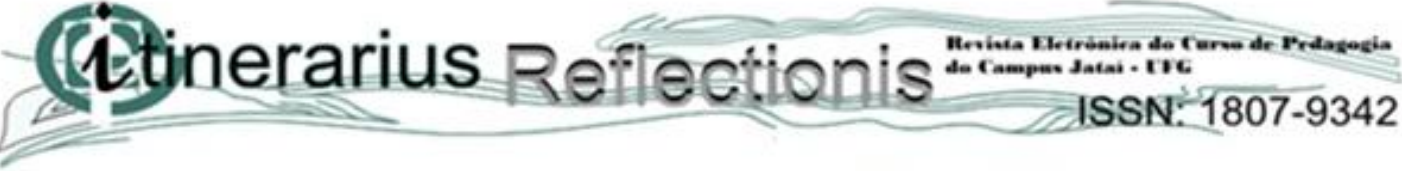

v.11, n. 1,2015

anos, principalmente, em face à urgência de se resolver os graves problemas socioambientais. Essa modalidade de educação tem sido apontada como um meio de aprendizagem no gerenciamento e melhora das relações entre as sociedades humanas e o meio ambiente, de modo integrado e sustentável (JACOBI, 2004; ZANETI, 2003).

Segundo Sachs (1993) e Jacobi, (2004), o desafio está em se pensar na passagem do conceito para a ação. Deste modo, a educação deve se orientar de forma decisiva para formar as gerações atuais não somente para aceitar a incerteza e o futuro, mas para gerar um pensamento complexo e aberto às indeterminações, às mudanças, à diversidade, à possibilidade de construir e reconstruir em um processo contínuo de novas leituras e interpretações do já pensado, configurando possibilidades de ação.

\section{A EDUCAÇÃO AMBIENTAL E A PROPOSTA DE UMA EDUCAÇÃo PARA O DESENVOLVIMENTO SUSTENTÁVEL}

A educação, em todas as suas formas, pode moldar o futuro de uma geração, modificando as atitudes das pessoas e repensando as práticas sociais, com base numa compreensão adequada e essencial do meio ambiente global e local, para construir uma sociedade planetária mais justa e ambientalmente sustentável. É um instrumento privilegiado para alcançar o desenvolvimento sustentável.

Uma vez vivendo em uma cultura de risco, muitas vezes os efeitos de determinadas atitudes escapam à nossa capacidade de percepção, fazendo com que ocorra um aumento significativo nas evidências de que tudo o que é feito hoje pode atingir não só a vida de quem os produz, mas as de outras pessoas, espécies e até gerações.

Em Tessalônica, Grécia, no ano de 1997, ocorreu a Conferência Internacional sobre Meio Ambiente e Sociedade, marcando uma nova direção na trajetória da Educação Ambiental, que a partir de então é colocada como um instrumento privilegiado para alcançar o desenvolvimento sustentável (UNESCO, 1997). A mesma Declaração vem afirmar que a educação e a consciência pública adequada, formam pilares da sustentabilidade. Nessa direção, a educação para a cidadania representa a possibilidade de motivar e sensibilizar as pessoas para 


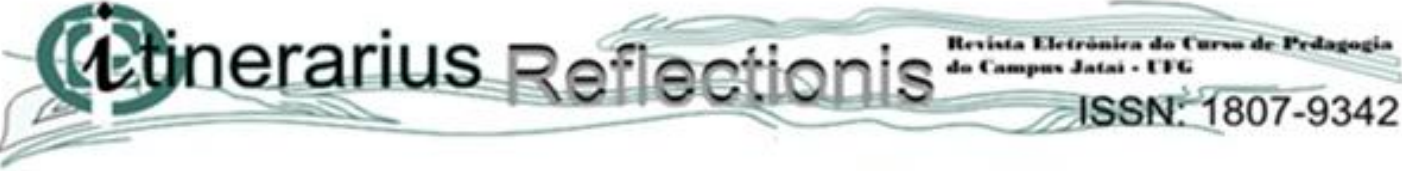

v.11, n. 1,2015

transformar as diversas formas de participação em potenciais fatores de dinamização da sociedade e para uma nova proposta de sociabilidade baseada na educação para a participação. Gadotti (2000) afirma que três anos antes da Conferência da Tessalônica, a UNESCO havia lançado a iniciativa internacional sobre educação para um futuro sustentável, reconhecendo que a educação era a 'chave' do desenvolvimento sustentável e autônomo.

Muitas questões sobre EA, como conceitos, objetivos, diretrizes e metodologias, associada ao desenvolvimento sustentável, foram idealizados ou desenvolvidos em diversas conferências internacionais, regionais e nacionais sobre meio ambiente. A Educação passa a ser concebida como um instrumento no processo do Desenvolvimento Sustentável.

Educação para o Desenvolvimento Sustentável (EDS) é um conceito dinâmico que compreende uma nova visão da educação que busca equilibrar o bemestar humano e econômico com as tradições culturais e recursos naturais do planeta para assumir a responsabilidade de construir um futuro sustentável. A educação que visa o futuro sustentável inclui questões-chave sobre o desenvolvimento sustentável no ensino e na aprendizagem. Pensamento crítico, reflexão sobre cenários futuros e tomadas de decisão de forma colaborativa, são competências que devem ser alcançadas e isso requer mudanças profundas no modo que a educação é frequentemente praticada nos dias atuais.

Deste modo, as raízes de uma educação para o desenvolvimento sustentável estão firmemente implantadas na EA, que, em sua breve trajetória, se esforçou para alcançar metas e resultados similares aos inerentes ao conceito de desenvolvimento sustentável, a educação deve se orientar de forma decisiva para formar as gerações atuais não somente para aceitar a incerteza e o futuro, mas para gerar um pensamento complexo e aberto às indeterminações, às mudanças, à diversidade, à possibilidade de construir e reconstruir em um processo contínuo de novas leituras e interpretações do já pensado, configurando possibilidades de ação.

A Organização das Nações Unidas realizou em Estocolmo, em 1972, uma declaração sobre o ambiente humano à qual continha uma série de princípios, que de maneira geral, dizia que é indispensável um trabalho de educação em questões 


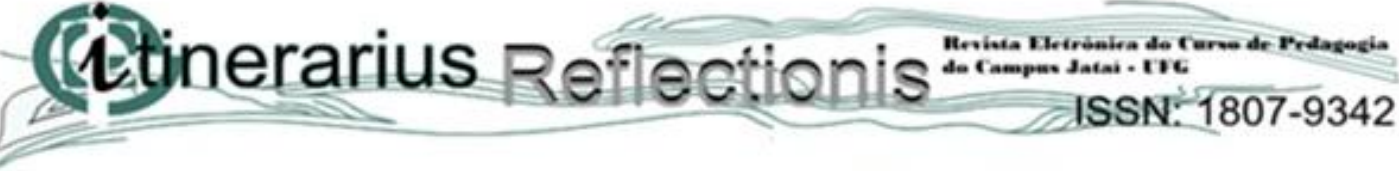

v.11, n. 1,2015

ambientais, visando tanto às gerações jovens como os adultos, dispensando a devida atenção ao setor das populações menos privilegiadas, para assentar as bases de uma opinião pública, bem informada e de uma conduta responsável dos indivíduos, das empresas e das comunidades, inspirada no sentido de sua responsabilidade, relativamente à proteção e melhoramento do meio ambiente, em toda a sua dimensão humana.

No Brasil, as práticas que relacionam a educação e o meio ambiente ainda são pouco difundidas na literatura, mas a crescente divulgação do discurso da sustentabilidade no contexto de um mundo globalizado recomenda a análise de seus significados e a avaliação de suas contribuições para o debate no país.

A Rio-92 aprovou, dentre outros acordos oficiais internacionais, a Agenda 21, que constitui uma cartilha de ações a serem desenvolvidas principalmente pelos Governos, com vistas à conciliação entre desenvolvimento e proteção ambiental. $\mathrm{O}$ capítulo 36 identifica quatro premissas no que tange a EDS: Promoção e Melhoria da Educação Básica, Reorientar a Educação existente em todos os níveis em direção ao Desenvolvimento Sustentável, Desenvolver Entendimento Público e Consciência da Sustentabilidade, e Treinamento. Endossa a necessidade de uma educação de conscientização pública para a sustentabilidade ambiental, por meio das comunidades científicas, das escolas, das ONGs, dos meios de comunicação e dos órgãos de governo (CONFERÊNCIA DAS NAÇÕES UNIDAS SOBRE MEIO AMBIENTE E DESENVOLVIMENTO, 2001).

Como forma de aplicar o cap. 36 da Agenda 21, a Cúpula Mundial sobre Desenvolvimento Sustentável (Johannesburgo, 2002) reforçou que não mais seria Educação Ambiental para alcançar o desenvolvimento sustentável, mas sim a "Década da Educação para o Desenvolvimento Sustentável 2005-2014”. Educação para a sustentabilidade, educação para um futuro sustentável, educação para o desenvolvimento sustentável passaram a ser expressões usadas como sinônimas nos documentos da ONU e da UNESCO a partir de então. O que leva a entender que a EDS nada mais é do é uma evolução da EA (UNESCO, 2005; BARBIERI E SILVA, 2011).

De acordo com Jacobi (2003) a dimensão ambiental insere diversos atores do universo educativo, pois necessita de diversas áreas do conhecimento, a capacitação 


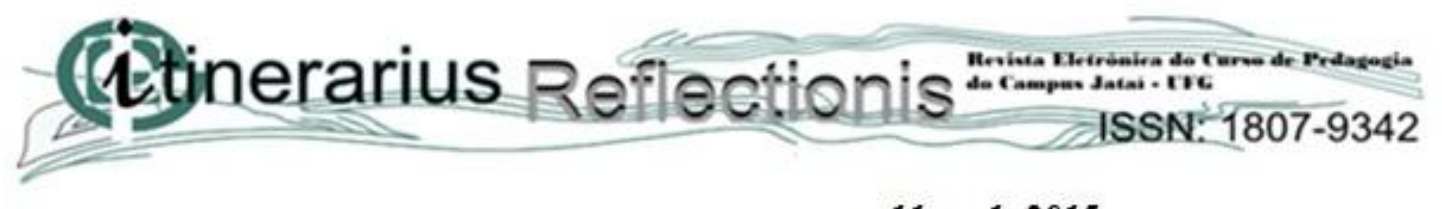

v.11, n. 1,2015

desses profissionais e de toda a comunidade preocupada com a construção do saber. Nos dias atuais em que a informação assume um papel cada vez mais relevante seja através da mídia, dos jornais ou até mesmo da internet, a educação representa a "possibilidade" de motivar e sensibilizar as pessoas para transformar as diversas formas de participação na defesa da qualidade de vida.

A Constituição Federal de 1988 em seu artigo 205 define que a educação, direito de todos e dever do Estado e da família, será promovida e incentivada com a colaboração da sociedade, visando ao pleno desenvolvimento da pessoa, seu preparo para o exercício da cidadania e sua qualificação para o trabalho. Em seu artigo 225, ela diz que todos têm direito ao meio ambiente ecologicamente equilibrado, bem de uso comum do povo e essencial à sadia qualidade de vida, impondo-se ao Poder Público e à coletividade o dever de defendê-lo e preservá-lo para os presentes e futuras gerações. É de responsabilidade do poder público promover a Educação Ambiental em todos os níveis de ensino e a conscientização pública para a preservação do meio ambiente.

Outras medidas oficiais surgiram após a Constituição como a publicação dos Parâmetros Curriculares Nacionais - PCNs (1997, 1998), que institui nos programas curriculares do ensino fundamental a dimensão ambiental; e a Lei 9.795/99, instituindo a Política Nacional de Educação Ambiental - PNEA, atrelando-a à Ética e às práticas sociais com as questões ambientais - locais, regionais, nacionais e globais. Visando integrar de forma equilibrada a educação e a sustentabilidade, é lançado em 1994, e reorganizado em 2004, o Programa Nacional de Educação Ambiental - ProNEA (LOUREIRO, 2008)

A Educação então é entendida como uma das ferramentas básicas e indispensáveis à sustentabilidade dos processos de gestão ambiental, que dissemina o diálogo, discute cidadania e incorpora nas práticas educativas a temática social e preocupações ambientais. Dessa forma, é um passo rumo à sustentabilidade e à prática dos seus ideais.

\section{CONSIDERAÇÕES FINAIS}

As críticas ao conceito de desenvolvimento sustentável e à própria ideia de sustentabilidade vêm do fato de que o ambientalismo trata separadamente as questões 


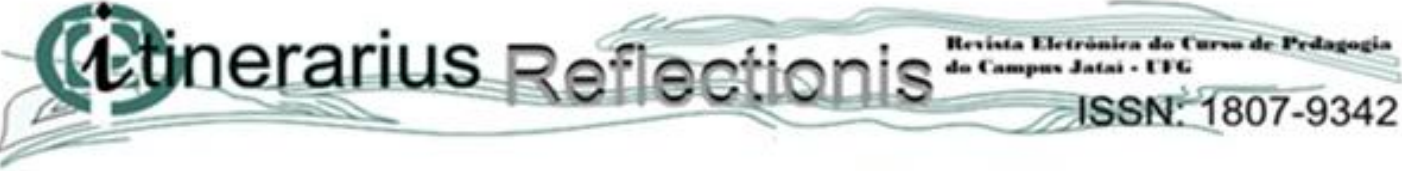

v.11, n. 1,2015

sociais das ambientais. Os problemas de que trata a ecologia afetam não somente o meio ambiente, mas também o ser mais complexo da natureza, o ser humano.

Diante da necessidade em resolver estes problemas socioambientais, a Educação Ambiental vem conquistando espaço e tem representado um papel relevante nos últimos anos. Essa modalidade de educação tem sido apontada como um meio de aprendizagem no gerenciamento e melhora das relações entre as sociedades humanas e o meio ambiente, de modo integrado e sustentável.

A EA deve estar incluída em todas as oportunidades de ensino, como um processo contínuo e estender para fora das instalações escolares, de modo a considerar o meio ambiente em suas múltiplas dimensões. Nesse sentido, o papel dos educadores professores (as) é essencial para impulsionar as transformações de uma educação que assume um compromisso com a formação de valores de sustentabilidade, numa perspectiva coletiva.

E o desafio em programar essa Educação para o Desenvolvimento Sustentável requer parcerias entre governos, comunidades acadêmicas e científicas, professores, ONGs, comunidades locais e mídia. Desta forma, Educação Ambiental e Desenvolvimento Sustentável podem e articular e se reforçar mutualmente, garantindo então, cidadãos conscientes e sensibilizados acerca do meio ambiente e dos problemas decorrentes das ações humanas.

\section{REFERÊNCIAS}

BARBIERI, J. C.; SILVA, D. Desenvolvimento sustentável e educação ambiental: uma trajetória comum com muitos desafios. Rev. Adm. Mackenzie, São Paulo, v. 12, n. 3, p.51-82, 2011.

BRASIL. Lei n $^{\circ} 6938$ de 31 de Agosto de 1981. Dispõe sobre a Política Nacional do Meio Ambiente.

COMISSÃO MUNDIAL SOBRE O MEIO AMBIENTE E DESENVOLVIMENTO: O nosso futuro comum. Universidade de Oxford. Nova Iorque, 1987

CONFERÊNCIA DAS NAÇÕES UNIDAS SOBRE MEIO AMBIENTE E DESENVOLVIMENTO (CNUMAD). Agenda 21. São Paulo: Secretaria de Estado do Meio Ambiente, 2001 


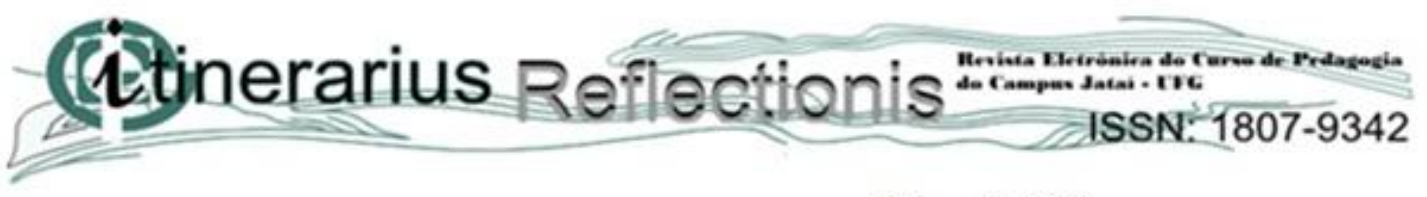

v.11, n. 1,2015

GADOTTI, M.. Pedagogia da Terra. São Paulo: Peirópolis, 2000.

GONÇALVES, D.B. Desenvolvimento sustentável: o desafio da presente geração.

Revista Espaço Acadêmico, $n^{\circ}$ 51. Agosto de 2005

JACOBI, P. Educação ambiental, cidadania e sustentabilidade. Cadernos de Pesquisa, São Paulo, n. 118, março 2003, p. 189-205

JACOBI, P. Desenvolvimento Sustentável e Educação - caminhos e desafios. 2004.

JACOBI, P. Educar para a Sustentabilidade: complexidade, reflexividade, desafiosIn: Revista Educação e Pesquisa- vol. 31/2- maio-agosto 2005, FEUSP.

LOUREIRO. C. F. B. Educação Ambiental no Brasil. Brasília: Ministério da Educação. Ano XVIII boletim 01 - Março de 2008.

MARCATTO, C. Educação Ambiental: conceitos e princípios. Belo Horizonte: FEAM, 1 ed. 2002.

NARDI, R; BASTOS, F; DINIZ, S. da. E. R. Pesquisas em ensino de ciências:

Contribuições para a formação de professores. São Paulo: Escrituras editora, 2004, n.5, p. $52-53$

ONU Brasil na Rio+20. Disponível em: www.radarrio20.org.br. Acesso em 05 de Jan de 2015.

SACHS, I. Estratégias de Transição para o século XXI - Desenvolvimento e Meio Ambiente. São Paulo: Studio Nobel - Fundação para o desenvolvimento administrativo, 1993.

UNESCO (Organização das Nações Unidas para a Educação, a Ciência e a Cultura). Educação Ambiental: as grandes orientações da Conferência de Tbilisi. Brasília: Ibama, 1997.

\section{Década da Educação das Nações Unidas para um Desenvolvimento}

Sustentável 2005-2014. Brasília: Unesco, 2005.

ZANETI, I.C.B.B., Educação Ambiental, Resíduos Sólidos Urbanos e Sustentabilidade. Um estudo de caso sobre o sistema de gestão de Porto Alegre, RS. 2003. 176 p. Tese de Doutorado - Universidade de Brasília. Centro de Desenvolvimento Sustentável. Porto Alegre - RS. 